\title{
Contact Versus Education: An Explorative Comparison Between the Contact and Education Strategy Considering Albinism Related Stigma in Tanzanian High Schools
}

\author{
T. M. M. De Groot ${ }^{1} \cdot$ P. Meurs ${ }^{1} \cdot$ W. Jacquet ${ }^{1} \cdot$ R. M. H. Peters ${ }^{2}$
}

Accepted: 25 February 2021 / Published online: 27 March 2021

(c) The Author(s) 2021

\begin{abstract}
Albinism in Tanzania causes fierce health-related stigma. Little research has focused on the impact of stigma reduction strategies aiming to reduce albinism related stigma. Therefore, this research assessed the impact of two short video interventions among high school students in Tanzania on their attitude towards people with albinism: a contact intervention $(n=95)$ and an education intervention $(n=97)$. A mixed method design was used. Directly before and after the interventions impact was measured among all participants through the Albinism Social Distance Scale for Adolescents (ASDS-A), knowledge items, and entertainment items. After these measurements focus group discussions were conducted, 16 in total $(n=80)$. Both interventions caused a significant increase in the levels of correct knowledge about albinism. The education intervention entailed a significant positive change in attitude measured through the ASDS-A, whereas the contact intervention did not have a significant effect. In terms of entertainment value, the respondents were more enthusiastic about the contact intervention. The study suggests that education interventions on their own can be a successful tool in decreasing albinism related stigma. Additionally, qualitative findings show many positive outcomes for the contact intervention. Therefore, we would recommend using a combination of these two interventions, which has also proved successful in the past. However, more research on the effect of a combination of the two strategies is recommended.
\end{abstract}

Keywords Albinism $\cdot$ Health-related stigma $\cdot$ Stigma reduction $\cdot$ ASDS-A

\section{Introduction}

Health-related stigma has a large negative effect on the lives of people with albinism in Sub-Saharan Africa (Affram et al., 2019; Braathen \& Ingstad, 2006; Bradbury-Jones et al., 2018; Brocco, 2016). Albinism is an inherited recessive genetic condition resulting in the

T. M. M. De Groot

groot.de.tjitske@gmail.com

1 Department of Educational Sciences, Vrije Universiteit Brussel, Brussels, Belgium

2 Athena Research Institute, Vrije Universiteit Amsterdam, Amsterdam, The Netherlands 
absence of the melanin pigment (Kromberg, 2018a). The absence of melanin causes the decreased or complete lack of pigment which causes the skin to lack the natural protection against UV-rays, which makes people with albinism sensitive to sunlight, resulting in a high risk to suffer from skin cancer (Lookingbill et al., 1995). The lack of melanin in the eyes also causes low vision (Williams, 2018). Besides these physical impairments the lack of melanin also causes the skin, hair and eyes of people with albinism to be light of colour, which is noticeable in a population where most of the people have a darker skin-colour.

In Tanzania albinism has led to fierce stigmatization that is accompanied by a large variety of myths and beliefs (Brocco, 2016; Bryceson et al., 2010; Kromberg, 2018b). One of the myths associated with albinism is the belief that the body parts of people with albinism provide good fortune, which has led to violent attacks on people with albinism (Bryceson et al., 2010; Cruz-Inigo, 2011). Other stories adding to the dehumanization of people with albinism are the belief that people with albinism are ghosts and they do not die but will at one moment just disappear (Baker et al., 2010; Brocco, 2015). People with albinism are often thought of as not being human (Imafidon, 2017). Stigmatization can have a far reaching negative impact on the lives of people with albinism. Among others stigmatization can negatively affect educational attainment and employment, it can also result in mental health issues and reduced access to necessary health care (Reimer-Kirkham et al., 2019). In a variety of studies public health interventions to reduce the stigmatization of people with albinism are recommended (Cruz-Inigo, 2011; Hong et al., 2006; Mostert, 2016; Uromi, 2014), however little research has assessed the impact of stigma reduction strategies in relation to albinism in Tanzania.

Nonetheless, a number of strategies to address health-related stigma in respect to other health-related conditions have been studied. Two often used strategies in stigma reduction are the contact strategy and the education strategy. Together with a third strategy, namely protest, which was found to be less effective by Brown et al. (2010), they form the three main stigma reduction strategies as considered by Corrigan and Penn (1999).

The contact strategy contains an interaction, either live or indirect, with someone with a stigmatizing condition, with the goal of reducing stigmatizing attitudes (Heijnders \& van der Meij, 2006). It is based on the contact hypothesis by Gordon Allport (1954), who stated that intergroup contact reduces prejudice. Contact has often proven to be an effective stigma reduction intervention (Pettigrew \& Tropp, 2006; Yamaguchi et al., 2013). For example, Brown et al. (2010) showed a decrease in stigma related to mental illness through a videocontact intervention. The potential of the contact strategy lies in its ability to build a personal relationship, generate empathy and correct misinformation (Allport, 1954; Brown et al., 2003; Pettigrew, 1998).

The education strategy entails the provision or amelioration of knowledge on a certain stigmatising condition, so that people are less likely to have stigmatizing feelings towards the stigmatized (Heijnders \& van der Meij, 2006). An advantage of the education strategy is its easy exportability (Corrigan et al., 2007). Some authors have demonstrated the success of education strategies (Cook et al., 2013; Corrigan et al., 2012; Tanaka et al., 2003), while others obtained less convincing results about the role education plays in stigma reduction (Brown et al., 2003; Corrigan \& Penn, 1999; Herek et al., 2002). Various authors recommend combining the education strategy with another strategy in order to achieve greater effectiveness (Brown et al., 2003; Stangl et al., 2012; Thornicroft et al., 2008).

Often, stigma-reduction interventions aim to be entertaining to attract peoples' attention and to increase impact. Singhal and Rogers (1999) describe this strategy as Entertainment Education (EE). EE functions as motivation for people to process the information provided in an intervention (Ritterfeld et al., 2005) and also improves this processing (Ritterfeld 
\& Weber, 2006). Additionally, EE increases participation (Murphy et al., 2011; Vorderer et al., 2006), and decreases counter arguing by the participants (Slater \& Rouner, 2002).

In stigma reduction research, few studies have compared the effectiveness of the contact and the education strategy (Brown, et al., 2010). Three comparison studies on mental illness stigma in the US demonstrate the greater effectiveness of contact interventions (Corrigan, et al., 2001, 2002, 2007). In this study, we will compare the effectiveness of the contact and education strategy in relation to albinism in Tanzania. We will also analyse the influence of the entertainment level on an intervention. In order to do so, this study evaluated the impact of two brief video interventions about albinism: (1) a contact intervention and (2) an education intervention. Through the comparison of these interventions we also hope to gain more insight in the role that knowledge plays in stigma reduction.

\section{Method}

To compare the contact strategy with the education strategy, a standardized intervention was chosen in the format of two video interventions: a movie focussing on personal contact with someone with albinism and one focussing on education about albinism. Both movies were based on a Tanzanian movie about people with albinism "Watu Kama Sisi" (People Like Us), which was created by Albino Peacemakers, an organization that supports people with albinism in Tanzania. For this study the researchers selected film clips from this movie and recombined them. For the contact interventions film clips were chosen of five people with albinism (a fish trader, a shop owner, a kindergarten teacher, a mother, a student) who introduced themselves and explained aspects of their lives, recombined in a movie of 10.46 min. As suggested by Penn et al. (2003) only film clips were chosen that unambiguously disconfirmed the stereotype of a person with albinism by displaying success stories. For the education intervention, film clips were chosen in which a doctor and two traditional healers explained about albinism, its causes and effects. This movie was 9.14 min total. For the movies see Appendix A.

The two movies were tested among high school students in four different schools. In three of these schools two groups were formed, one group saw the contact intervention and one group saw the education intervention. To gain more insight in the difference between the effects of both intervention the respondents inn the last school that participated in the research, school 4, saw both movies. A pre-test post-test study design was used. A pretest was conducted right before the intervention, and a post-test straight after the intervention. In school 4, students had an extra survey after the viewing of the second movie, as explained below. Afterwards focus group discussions (FGDs) were conducted with a selection of the respondents.

The quantitative measures used in the pre- and post-test are the following:

- The Albinism Social Distance Scale for Adolescents (ASDS-A) Changes in attitude towards people with albinism were measured through the 12-item ASDS-A, measuring social distance (e.g. S-05 How would you feel to have someone like John/Joyce as a family member?). Answer possibilities: I do not have a big problem (1 point), I do not have a problem ( 2 points), I do have a problem (3 points), I do have a big problem (4 points). Social distance scales have proven to be a proper measurement tool in stigma research (e.g. (Adewuya \& Makanjuola, 2005; Koller \& Stuart, 2016; 
Peters, et al., 2015). This particular scale has been validated for the use with albinism in Tanzania (de Groot et al., 2020).

- Knowledge items To measure a change in correct knowledge, 12 items were developed accordingly. Items were based on information about albinism that many people in Tanzania do not know according to experts in the field. These experts consisted out of people with albinism, staff members of organizations working to improve the lives of people with albinism and researchers on the topic of albinism. Three items (K-01-K-03) are 'knowledge explanation items', for which a written explanation is required by the respondent (e.g. K-01 'Do you know the reason for albinism?', in case respondents say that they know the answer to this question they have to provide clarification). These items were followed by closed-ended 'knowledge-items' (K-04-K-12) (e.g. K-04 Do you think albinism is contagious?). Answer possibilities were: Yes, No, I don't know.

- Entertainment items To measure the entertainment level of the interventions six items were added, based on items used by Ritterfeld and Jin (2006), asking the respondent how they felt about the intervention (e.g. E-01 The show was very entertaining). The items were scored on a 5-point agreement scale.

In the pre-test demographic data was gathered, among others about age, gender, tribe, place of birth, and familiarity with people with albinism. The pre-test consisted out of demographic questions, knowledge items, and the ASDS-A. The post-test consisted out of the knowledge items, the ASDS-A, and Entertainment items. The extra survey, conducted in school 4 after the viewing of the second movie, existed out of Entertainment items and two comparison question for which written clarification had to be provided (C1. Which movie did you like more? C2. From which movie did you learn more?).

To get an impression of which parts of the movie were interesting to the respondents FGDs were conducted after each intervention. The method of FGD was chosen because in the experience of the researcher, adolescent respondents in Tanzania feel more at ease talking to an adult researcher when they are in a familiar group. Respondents were asked the following questions (or variations of these questions): "What did you see in the movie?", "What did you learn from the movie?", "What did you/didn't you like in the movie?", "Was there something missing in the movie?" and "Do you have any questions?". In school 4, respondents were also asked to compare the first and the second movie: "Which movie did you prefer and why?" and "From which movie did they learn more and why?". For each FGD four to six students were selected. Participants were selected by dividing the group in subgroups based on gender, followed by systematic sampling from these two groups, students were selected based on regular intervals from the total sample (e.g. every fourth student in the row, depending on the number of students in the total sample).

To control for the possible effect of the pre-test as an intervention itself in reducing stigmatizing attitudes (de Groot et al., 2020), approximately only half of the respondents filled out the pre-test, the other half was provided with a substitute survey only existing out of demographic questions, after which they were presented with a written story about animals.

Schools and students participated on a voluntary basis, this was explained to them by the researcher and an assisting teacher. This study was part of a larger research that has been approved by the Tanzanian Commission for Science and Technology (COSTECH), from whom a research permit has been obtained. The headmasters in charge of the participating schools provided the researcher with written consent, and oral consent was obtained from the participating students. 


\subsection{Sample}

The sample consists of students from four different private high schools in Mbeya, in the south of Tanzania, and covered the first four classes of high school (in Tanzania these are called the four forms of the ordinary level). The choice for a private school was based on convenience. The schools and students were selected based on their availability. The participating groups were purposefully sampled so that all forms would be represented. The researcher also tried to have a balance of gender in the samples. Groups existed out of students from the same form, except for the group students in school 3 where forms 1 and 3 were combined. There were no children with albinism attending the schools in which the research took place.

\subsection{Data Analysis}

Quantitative data was analysed using IBM SPSS statistics 25 (SPSS Inc., Armonk, NY.). Samples were compared using Pearson Chi-Square. Respondents that only participated in the pre- or post-intervention were removed from the data set (two respondents from post-test, three respondents from pre-test).

Reliability of the scales was calculated using Cronbach's alpha. Differences between pre- and post-test of the same interventions on item level were calculated through McNemars test for the knowledge items (which were dichotomised by 1 . Correct answer, 2. Wrong answer existing out of the wrong answer and I don't know), and through Wilcoxon Signed-Rank Test for the ASDS-A. A difference variable for the ASDS-A items was calculated to get an insight in the impact of the intervention on the attitudes of the respondents towards people with albinism (post-test score minus pre-test score). On scale level all items were computed and compared using Wilcoxon Signed-Rank Test.

Differences between interventions were calculated using the Mann-Whitney $U$ test for non-parametric data. Correlation between the scales based on knowledge items (K-04-K-12) and the ASDS-A was calculated through Spearman's rank correlation. Differences between groups within the sample are calculated through the Mann-Whitney U or Kruskal-Wallis test.

Qualitative data was analysed using NVivo 12. The FGDs were recorded and transcribed. The transcription was coded through recurring themes in the discussions, after which the interventions were compared, and the data was summarized so that conclusions could be drawn.

\section{Results}

\subsection{Quantitative Data}

\subsubsection{Demographics}

Demographics are presented in Table 1. In total 192 respondents $(52.1 \%$ male, $47.9 \%$ female) participated in this study, 95 students participated in the contact intervention, 


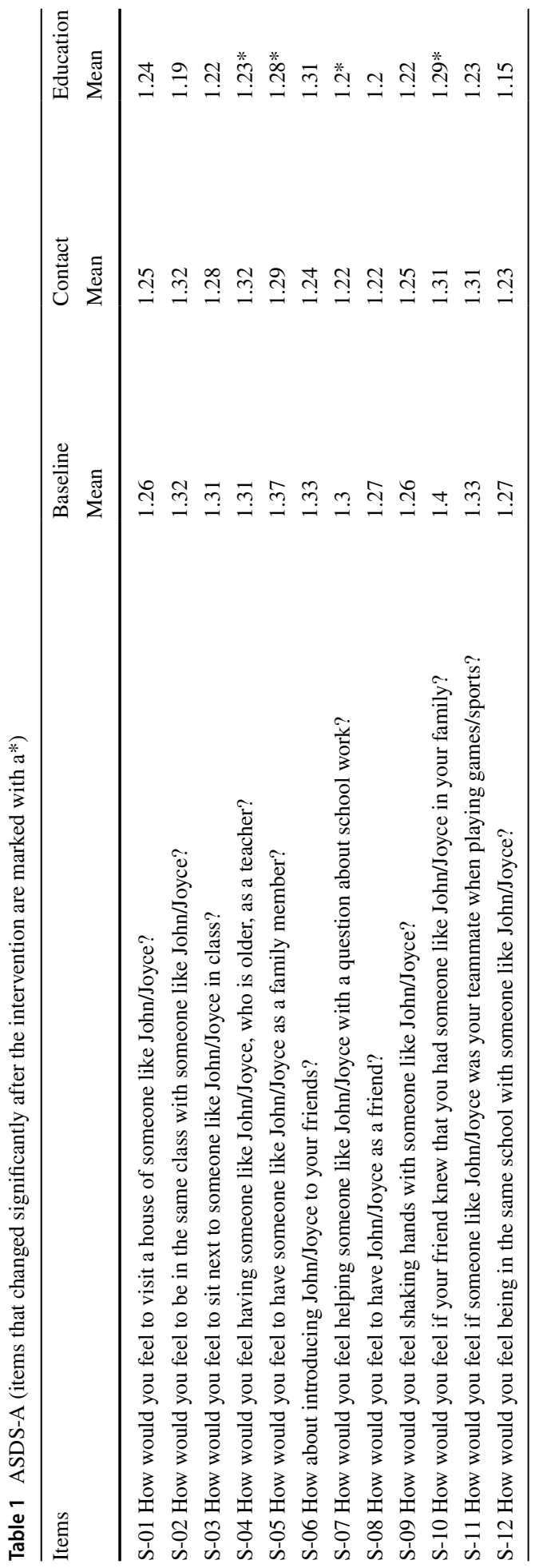


97 in the education intervention. The baseline study was filled out by 103 respondents, the substitute survey was filled out by the remaining respondents $(n=89)$.

Respondents from form 1, 3 and 4 of ordinary level education participated in this study. Due to school exams, no sample of form 2 students was found to participate in the education intervention. Since all schools were boarding schools only $40.1 \%$ of the respondents came from Mbeya the others came from a large variety of other areas in Tanzania. A large variety of tribes (54) was represented in the sample including Mnyakyusa $(n=52)$, Mkinga $(n=17)$ and Mchaga $(n=10)$. The parents' education backgrounds varied, but all were literate. Almost everyone (98.4\%) had seen someone with albinism and $87.7 \%$ knew someone with albinism. Of the respondents $4.2 \%$ indicated to have a family member with albinism. Ages varied between 13 and 26 years old, with an average age of 16.35 . There are no significant differences between the samples of the two different interventions.

\begin{tabular}{llll}
\hline Variables & & Respondents (n=192) \\
\hline School & 1 & $28(14.6 \%)$ & \\
& 2 & $69(35.9 \%)$ & \\
& 3 & $55(28.6 \%)$ \\
Gender & 4 & $40(20.8 \%)$ & \\
Form & Men & $100(52.1 \%)$ & \\
& Women & $92(47.9 \%)$ & \\
& One & $43(22.4 \%)$ & \\
Seen someone with albinism & Two & $22(11.5 \%)$ & \\
& Three & $85(44.3 \%)$ & \\
Know someone with albinism & Four & $42(21.9 \%)$ & \\
& No & $3(1.6 \%)$ & \\
Family member with albinism & No & $189(98.4 \%)$ & Father \\
& Yes & $24(12.3 \%)$ & $33(16.9 \%)$ \\
& No & $168(87.7 \%)$ & $22(11.6 \%)$ \\
Education level parents & Yes & $8(4.2 \%)$ & $42(21.7 \%)$ \\
& & Mother & $15(7.9 \%)$ \\
& Literate & $38(19.7 \%)$ & $66(34.4 \%)$ \\
& Primary school & $37(19.1 \%)$ & $14(7.4 \%)$ \\
\hline
\end{tabular}

\subsubsection{Social Distance}

The reliability of the ASDS-A scale is $\alpha=0.941$ in the pre-test (12 items). No significant difference was found on the ASDS-A scale between respondents who filled out the substitute survey and survey 1 .

After the contact intervention no significant change was found when comparing the ASDS-A scores from before and after the intervention. This score existed out of a sum of 
the scores of all items of the ASDS-A. Also, on individual items there was no significant change after the contact intervention.

With regard to the education intervention, a significant change was found after this intervention $(Z=-3.196, p=0.001)$. Item-wise a significant decrease of social distance took place on four items: S-04 How would you feel having someone like John/Joyce, who is older, as a teacher?; S-05 How would you feel to have someone like John/Joyce as a family member?; S-07 How would you feel helping someone like John/Joyce with a question about school work?; S-10 How would you feel if your friend knew that you had someone like John/Joyce in your family? (See Table 1).

When comparing the outcomes of the two interventions, the necessity of equal samples for both interventions was met, no significant difference was found on the ASDS-A before the intervention between the intervention groups. However, also after the intervention no significant difference between the samples was found on the sum-scale and item-wise. Additionally, there was no significant difference between the intervention groups on the difference variable sum-scale. Only item-wise, the difference variable, showed one significant difference on item S-04. How would you feel having someone like John/Joyce, who is older as a teacher? $(Z=-3052, p=0.002)$.

\subsubsection{Knowledge}

According to the McNemars test there was no significant change in knowledge after the contact intervention. After the education intervention four items portrayed a significant difference in knowledge (see * in Table 2 below): K-01 Do you know the reason for albinism?; K-02 Do you think albinism is inherited?; K-03 Do you know what to do to help someone with albinism?; K-12 A person with albinism does not die but just disappears?.

Subsequently, the intervention effects were compared. Before the interventions the intervention groups are equal according to Pearsons Chi-Square, except for item K-11 'A person with albinism can get skin cancer from being in the sun?' on which the education intervention group portrayed to be more knowledgeable. After the intervention there was a significant difference between the contact and the education sample on four items (see highest italic scores in the table below). In three cases the education intervention group

Table 2 Knowledge Items (items that changed significantly after the intervention are marked with a*)

\begin{tabular}{lllc}
\hline Items & Pre-test & Contact & Education \\
\hline K-01 Do you know the reason for albinism? & 34.5 & 33.8 & $56.6^{*}$ \\
K-02 Do you think albinism is inherited? & 30.2 & 31 & $50.6^{*}$ \\
K-03 Do you know what to do to help someone with albinism? & 51.9 & 66.7 & $64.4^{*}$ \\
K-04 Do you think albinism is contagious? & 80.2 & 87.1 & 83.2 \\
K-05 Do you think a person with albinism will turn blind? & 44.3 & 50.6 & 45.3 \\
K-06 A person with albinism can get a child without albinism? & 85.6 & 94.7 & 85.4 \\
K-07 Persons with albinism can learn how to read and write? & 98 & 98.9 & 99 \\
K-08 People with albinism need to eat special food? & 43.1 & 52.7 & 51.1 \\
K-09 A person with albinism can go to a normal school? & 89 & 96.8 & 91.8 \\
K-10 A person with albinism is bewitched? & 96.1 & 95.8 & 99 \\
K-11 A person with albinism can get skin cancer from being in the sun? & 84 & 75.3 & 94.8 \\
K-12 A person with albinism does not die but just disappears? & 81.4 & 90.4 & $93.8^{*}$ \\
\hline
\end{tabular}


scored higher than the contact intervention group: K-01 Do you know the reason for albinism?; K-02 Do you think albinism is inherited?; K-11 A person with albinism can get skin cancer from being in the sun? In one case the contact intervention group scored higher: K-06 A person with albinism can get a child without albinism?

The (pragmatic) sum scales (K-04 up to K-12) $(\alpha=0.582)$ of both interventions portrayed significantly improved correct knowledge concerning albinism (contact intervention $Z=-1.990, p=0.047$; education intervention $Z=--2.085, p=0.037$ ). Before and after the intervention no significant difference between intervention groups was found on the pragmatic knowledge sum scale.

\subsubsection{Entertainment}

The reliability of the entertainment scale is $\alpha=0.594$. According to Terwee et al. (2007) this is below the criterion for good internal consistency $(0.7<)$ and the scale is therefore not reliable. When looking at pragmatic scale level and item level no difference in entertainment level between the interventions can be found (Table 3).

\subsubsection{Correlation Between Scales}

There is a low correlation between the items measuring correct knowledge (the Knowledge items) and the scale measuring peoples attitude towards people with albinism (the ASDSA). The correlation between these scales in the pre-test is $0.215(p=0.05)$, and in the posttest $0.246(p=001)$.

\subsubsection{Differences Between Groups}

When looking for differences in scores between different groups within the sample one finds a significant difference between the scores of boys and girls on the knowledge questions after the intervention (on the total sample) $(p=0.002)$. There is a significant difference based on gender after the contact intervention $(p=0.001)$, and not after the education intervention ( $p=0.184)$. The boys seem to have more knowledge after the contact intervention than the girls. When looking further into this difference, it seems the interventions both have been significantly effective in improving correct knowledge for the boys, but have not been significantly effective for the girls.

The form that the students attend made a significant difference on the knowledge level and ASDS-A post-test $(p=0.001$, and $p=0.018)$. When comparing forms, a significant

Table 3 Entertainment items (*recoded items)

\begin{tabular}{lll}
\hline Items & $\begin{array}{l}\text { Contact } \\
\text { Mean }\end{array}$ & $\begin{array}{l}\text { Education } \\
\text { Mean }\end{array}$ \\
\hline $\begin{array}{l}\text { E-01 The show was very entertaining } \\
\text { E-02 I had the sense of being pulled right }\end{array}$ & $\begin{array}{l}3.86 \\
\text { into the show }\end{array}$ & $\begin{array}{l}3.91 \\
\text { E-05 I very much enjoyed the show }\end{array}$ \\
$\begin{array}{l}\text { E-06 The show was very involving } \\
\text { E-03 The show did not interest me* }\end{array}$ & 4.39 & 4.49 \\
E-04 I wasn't involved in the show* & 3.89 & 4.45 \\
\hline
\end{tabular}


difference is found on the knowledge re test between form 1 and 4 and the ASDS-A before and after the intervention (lower mean ranks for form 4). There is also a significant difference between form 1 and 3 on the re-test of the knowledge and the ASDS-A scale (lower mean ranks for form 3). There is also a significant difference between the pre-test of form 2 and 1 but form 2 has a very low $n$ (11).

There is a significant difference between the education level of the father and the post knowledge scale.

\subsubsection{Extra Survey}

In school 4 respondents were asked to watch both movies. When asked comparison question 1 (Which movie did you like more?) in the extra survey, 32 respondents preferred the contact movie, and 10 the education movie. Respondents mentioned they preferred the contact movie because: 'they learned people with albinism are normal people/like you and I' $(n=10)$, people with albinism marrying people without albinism $(n=6)$, they learned people with albinism could have children without albinism $(n=5)$ and it was about assisting people with albinism $(n=5)$. Among the respondents who preferred the education movie the most often provided reason was that the movie was about the fact that people with albinism are normal human beings/like you and I $(n=5)$, and because people with albinism should not be discriminated $(\mathrm{n}=5)$.

As a result of comparison question 2 (From which movie did you learn the most?) 30 respondents preferred the contact movie and 11 the education movie (1 missing). The respondent who found the contact movie more educational expressed this was among others because it was about real-life situations $(n=5)$, positive situations such as the marriage of someone with albinism $(n=3)$, or negative such as discrimination $(n=8)$. The reason for stating one learned more from the education movie was mostly that this intervention explains the cause of albinism $(n=4)$ and people with albinism are normal human beings $(n=4)$.

\subsection{Qualitative Data}

In total 16 FGDs were conducted, in which 80 respondents participated (43 male, 37 female).

\subsubsection{Focus Group Discussion After Contact Intervention}

When discussing the contact intervention, respondents mostly referred to two of the five characters who were portrayed in the movie: the form four student (named specifically in seven FGDs), and the fish trader (named specifically in six FGDs). The student might be recalled because she was in the same phase of life as the respondents, secondary school students. Through these two characters, respondents seem to have realised that people with albinism have the same capabilities as people without albinism. This view was confirmed in six FGDs. Two illustrative quotes:

... now we learn that albinos can stand on their own without even the help of anyone else and can make changes, like the student in form four going to the NECTA examination on the eleventh month (Student, male). 
There was a fish trader who was stigmatized by some people that, even with his business, people would not buy something from [someone with] his condition. However, he still has clients and he is well known in the community. So, he values his business just like other people. Like normal people (Student, female).

Some themes recurred in the interviews such as the capabilities of people with albinism and marriage. The majority of the participants remembered the fish trader because of his marriage to someone without albinism (named in seven focus group discussions) and his children without albinism (in six focus group discussions). This was a recurring theme in the FGDs, respondents for example mentioned the following about this:

I was surprised, I do not believe at all that somebody would agree to marry somebody who has albinism. [...] that [a person with albinism marrying someone without albinism] surprised me and made me see that each and everything is possible under the sun (Student, male).

What we've been able to learn from the movie is that if an albino gets married to another, he can be found with a non-albino child. But also, we should not exclude albinism because they are capable of doing things that we and others with normal skin can do (Student, male).

One interviewee directly related this lesson to himself:

What I have come to discover and know more about after watching the movie is that, I realized that I could marry an albino and then we would have beautiful children like the albino who married a non-albino woman and gave birth to three children who are normal non-albinos (Student, male).

Commenting on the issue of marriage, one interviewee stated that people with albinism also have the right to be loved:

... even this albino has the right to be loved as normal people [...]. Before the movie I thought albino marrying an ordinary man is a dream, so why? It's hard to be accepted by someone with whom a relationship is difficult. And that's why we see even her parents, said to their daughter: why would you marry someone with the skin of an albino, but the girl stood in her position saying I love this one. That fact has shown that even albinism has the power to be loved (Student, female).

In one case participants had to laugh when they saw the fish trader in the movie, later they explained that they laughed because they thought people with albinism were too weak to sell fish, as one interviewee said:

It is precisely here [with the laughing because of the movie] that we see why a person with albinism even in the ordinary society around us becomes oppressed by the people. He is considered a weak person who can't work, we say you can't compare him to a normal coloured (person), we think he is a man who can't do market business, that he can't sell fish, which is why even when people take the picture he sells fish and start laughing (Student, male).

Respondents stated that people with albinism should not be discriminated (in eight focus group discussions), and they should be supported (eight focus group discussions). In all focus group discussions (ten) respondents discussed that people with albinism are normal people/like them/human, illustrated by the following quote: 
They can do things that are good for the world, because there are some people who are albino, there are doctors who are albinos and in many services there are workers with albinism. That means, albinos are people like us, have all rights like us, let us say: rights to live, worship and all rights that humans have in this world (Student, female).

When the respondents were asked what was missing in the movie the following issues came up. Firstly, in two FGDs the respondent mentioned that stories about the problems of people with albinism should be included. The bad treatment of people with albinism was discussed in six FGDs and in seven FGDs respondents referred to superstitious beliefs about people with albinism. Secondly, in one focus group discussion it was mentioned that more should be explained about the cause of albinism, which was endorsed by the questions respondents had after the intervention: three times participants asked for more explanation about the cause of albinism. Besides that, three times respondents asked about the eye problems of people with albinism, other questions were asked about the skin of people with albinism and how to assist students with albinism. One respondent asked afterwards if the body parts of people with albinism bring good fortune.

\subsubsection{Focus Group Discussion After Education Intervention}

Main themes after the education intervention were the cause of albinism, discrimination of people with albinism, and witchcraft. After the education intervention the respondents discussed the cause of albinism (in all ten FGDs). As an example, one respondent explained that before the intervention they thought the cause of albinism was witchcraft: "but when I saw the movie I learned that, I have learned that it is inherited from parents (Student 1, S2 K 1"). However, in two FGDs respondents provided the wrong explanation about the cause of albinism, one respondent expressed: albinism is caused by parents lacking vitamin $\mathrm{G}$ and another thought albinism was caused by a parasite.

Respondents often stated that one should not discriminate people with albinism (mentioned in seven out of eight FGDs) and people with albinism are human beings/like you and I/normal people (mentioned in all eight FGDs). This was summarized by the two quotes below:

So, first we were isolating them [people with albinism] as if they were nobody. We were isolating them like they are not human creatures, but after the education we got, you know... We can now interact with them (Student, female).

Albinos, at first, we were excluding them but now I have learned that albinos are just like other people and they should not be isolated (Student, female).

In all eight FGDs witchcraft in general and some superstitious beliefs were discussed. Below myths are listed that came up in the FGDs:

- Body part of people with albinism bringing good fortune (in six FGDs)

- Albinism brings bad fortune (in one FGD)

- People with albinism do not die but disappear (in one FGD)

- People with albinism are bewitched (in one FGD)

- People with albinism do not have value (in one FGD)

- Albinism is contagious (through touching) (in one FGD) 
Some respondents learned that they will not get rich by selling body parts of people with albinism, as stated by the respondent below:

I am going to talk about what I learned. [...] I thought that, if you get the albino albinism organ, you can get wealth. So, after watching that movie now I have got the confirmation... That's it, we cannot get wealth from albinos (Student, male).

When asked what was missing in the movie, it was suggested more information should be provided about the eyes of people with albinism (in two FGDs) and it was suggested to provide more information on the skin of people with albinism (in one FGD). Additionally, in two FGDs respondents asked questions about the eyes of people with albinism, and in one FGD someone mentioned not to have understood part of the explanation about genetics. Interestingly, in one FGD it is suggested to show people with albinism that have succeeded: in another FGD it was mentioned they missed someone with albinism in the movie: "he (a person with albinism) could explain that, he is just a person like us and he could be some of thing that he or she may like to prefer like other people who have not got albinism (Student, female)".

The traditional healers in the movie were named in four FGDs, the medical doctor in three FGDs). The two traditional healers in the movie explain that people with albinism are just normal human beings and that the myths, about for example the body parts of people with albinism, are not true. The medical doctor explains about the scientific genetic causes of albinism in the movie. The explanation of these healers seemed to have made an impression on the respondents.

\subsubsection{Comparison of Interventions}

When asking the respondents is school 4, who saw both the movies, which movie they preferred, 14 out of 21 respondents preferred the contact intervention. The following quote summarizes the respondents' view on the contact intervention:

Yeah! It [the contact movie] has taught us more than the first [education movie] because we have seen a person with albinism can marry a non-albino person and may give birth to a non-albino child (Student, male).

To which another student added:

I [liked the] second movie [contact movie most], because it teaches me that someone with albinism can do great things, you see? As far as I knew a person with albinism maybe cannot read, could not possibly end up in lower education, see? Like the sister (student with albinism in the movie) who proceeded to form four see? So that's what I learned (Student, male).

However, the respondents who preferred the contact movie also noticed that they learned a lot from the doctor in the other movie who explained about albinism. Even though respondents are still wondering after the two interventions how albinism happens. Seven out of 21 respondents preferred the education movie, because they liked the proper explanation about albinism.

Additionally, in many of the quotes accompanying the FGDs in relation to both interventions we can observe changes in attitude but we also observe some remaining stigma. In the wording of the respondents subtle stigma can be noted, for example by describing people without albinism as 'normal people' or people prefer having children without albinism. 


\section{Discussion}

This study evaluated the impact of two strategies to reduce albinism related stigma and increase knowledge on albinism in a high school setting in Tanzania: the contact strategy and the education strategy. Research focussing on comparing the contact and education strategy is limited and has mainly focused on mental health-related stigma in the US (Corrigan, et al., 2001, 2002, 2007). The effect of the strategies has been measured through mixed methods: the ASDS-A, knowledge items, entertainment items and FGDs.

Firstly, through quantitative methods this study found the following. The contact intervention did not have significant influence on the change in attitude towards people with albinism measured through the ASDS-A. These findings contradict other studies in which contact interventions were associated with improved attitudes (Pettigrew \& Tropp, 2006; Yamaguchi, et al., 2013). The contact intervention did cause a significant increase in correct knowledge on albinism. The education intervention had a significant influence in reducing the student's social distance towards people with albinism and increased levels of correct knowledge. Our findings are not in line with previous studies that suggest that an educational intervention by itself is not very effective in influencing stigmatizing attitudes (Brown et al., 2003; Corrigan \& O'Shaughnessy, 2007; Corrigan et al., 2001, 2002; Herek et al., 2002; Stangl et al, 2012; Thornicroft et al., 2008). Penn et al., for instance state that educational strategies alone, like this one, are unlikely to affect all aspects of psychiatric stigma and that other strategies, including personal contact, may be required. Even though the contact strategy was not significantly effective in reducing social distance towards people with albinism and the education strategy was, no significant difference could be found between the outcomes of both interventions, nor between their effects. Therefore, it can not be concluded that one intervention is more effective than the other.

Secondly, in terms of entertainment value of the intervention, quantitative findings show that respondents found both interventions entertaining. However, one should be careful drawing conclusions from the entertainment scale because of the low reliability of the scale. Qualitative findings indicate that respondents preferred the contact intervention over the education intervention.

Thirdly, the focus group discussions after the interventions provided us with the following insight. After the contact intervention respondents kept on emphasizing that people with albinism are normal human beings. Contrasting the outcomes of the quantitative data, this might point to an effect of the intervention in reducing stigmatizing attitudes. The qualitative findings point towards the need to further refine the quantitative instrumentation. The quantitative approach is easily scalable, and anonymity can provide safety if that is appreciated as such by the respondents. When refined and applied on a larger sample the quantitative approach might reveal significant differences.

The characters that were mostly recalled after the contact intervention, a form four student and a fish trader, might be recalled because respondents identify with aspects of the lives of these characteristics. Identification with characters in interventions can influence behavioural change (Basil, 1996; Kuhlmann et al., 2008). These characters named above seemed to be the strength of the contact intervention, living up to the expectations of a contact intervention to generate empathy and correct misinformation (Allport, 1954; Brown et al., 2003; Pettigrew, 1998).

In relation to the education intervention, the qualitative findings show that especially learning about the cause of albinism was important to the respondents. This is in accordance with the recommendation of Masanja et al. (2014) who recommend the provision 
of knowledge to improve the attitudes of children towards PWA and differs from Brocco (2015), who stated that even though (bio) medical knowledge about albinism was lacking in the community, perceptions about PWA did change. As recommended by Heijnders and Van der Meij (2006) and Penn et al. (2003) the education intervention succeeded in providing respondents with enough disconfirming knowledge to change people's beliefs and stereotypes, as could be read in the qualitative findings.

The outcomes of our study again prove the importance of using mixed methods in evaluating stigma reduction interventions. The quantitative findings point to a lack of effectiveness of the contact intervention, which is interesting to follow up. Especially, because the qualitative findings provide insight in how the contact with someone with a stigmatizing condition was of importance to the respondents.

Additionally, the use of the extra survey provided us with the opportunity to conclude that the survey did not function as an intervention itself. Respondents who filled out the extra survey before the intervention instead of the pre-test did not differ in outcome on the post-test compared to the respondents that filled out the pre-test. This is contrary to the possible limitations of the measurement instrument as presented in de Groot et al. (2020).

\subsection{Limitations}

This research is subject to several limitations. Firstly, future research is necessary to determine the outcomes of these types of interventions on the longer term. Secondly, one needs to be careful with generalizing the outcomes of this research: the data collection took place in private high schools which highly effects the sample, e.g. the education level of the parents of the children is relatively high: which can influence the outcomes. Also the study was carried out among a specific age group, namely high school students. It would also be of interest to carry out this study among different age groups: e.g. elementary students. Additionally, it is of interest to further research the difference in effect of the interventions which was found between boys and girls before generalizations can be made. Thirdly, one should be aware the attitudes of the respondents were only measured though a social distance scale, which might be sensitive to socially desirable answering but also does not tell us anything about how people would actually behave towards people with albinism. Fourthly, it should be noted that both strategies were videos and do not consist of a live intervention. This is a factor which could also have influenced the outcome of the interventions, even though other research has proven this does not have an influence (Reinke et al., 2004).

\section{Conclusion}

The outcomes of this study show the importance of the implementation of, and research into stigma reduction interventions. Findings suggest among others that the education strategy, in the form of a short educational movie on albinism, can be effective in reducing stigmatizing attitudes and improving knowledge among high school students in Tanzania towards people with albinism. Since these findings contradict some past research, that has mostly been carried out in the US and Europe, it would be of interest to set up a larger research on this topic and to research the outcomes of different stigma reduction strategies in other contexts and in relation to other stigmatizing conditions. Qualitative findings also showed many positive responses to the contact strategy. Elements that were missing in one 
strategy could be found in the other, which points again to the complementary value of both strategies. Giving the positive responses with regards to different aspects of the contact intervention and the education intervention, we would recommend using both, since a combination of these two interventions also have proven successful in the past (Brown et al., 2003; Peters et al., 2015). This would open up opportunities for a comparative research.

We would like to emphasis the advantages of the use of these films were that they are easily to disseminate and do not require the presence of a teacher (for the education intervention) nor a person with albinism (for the contact intervention). However, we should consider that, not all schools in Tanzania will have the means and/or infrastructure in place to play these movies. We would recommend (local) governments and other stakeholder to pay attention to stigma reduction initiatives, and their evaluation, which are often carried out by other parties. By a cooperation between all stakeholder, including different government levels, the knowledge on stigma reduction interventions can grow, as can their effectiveness.

Supplementary Information The online version contains supplementary material available at https://doi. org/10.1007/s10699-021-09788-z.

Funding This research has been funded by VLIR-UOS through a VLADOC scholarship that financed the $\mathrm{PhD}$ researcher of the first author.

\section{Declaration}

Conflict of interest On behalf of all authors, the corresponding author states that there is no conflict of interest.

Open Access This article is licensed under a Creative Commons Attribution 4.0 International License, which permits use, sharing, adaptation, distribution and reproduction in any medium or format, as long as you give appropriate credit to the original author(s) and the source, provide a link to the Creative Commons licence, and indicate if changes were made. The images or other third party material in this article are included in the article's Creative Commons licence, unless indicated otherwise in a credit line to the material. If material is not included in the article's Creative Commons licence and your intended use is not permitted by statutory regulation or exceeds the permitted use, you will need to obtain permission directly from the copyright holder. To view a copy of this licence, visit http://creativecommons.org/licenses/by/4.0/.

\section{References}

Adewuya, A., \& Makanjuola, R. O. (2005). Social distance towards people with mental illness amongst Nigerian university students. Social Psychiatry and Psychiatric Epidemiology, 40, 865-868.

Affram, A. A., Teye-Kwadjo, E., \& Gyasi-Gyamerah, A. A. (2019). Influence of social stigma on subjective well-being of persons with albinism in Ghana. Journal of Community \& Applied Social Psychology, 29, 323-335.

Allport, G. W. (1954). The nature of prejudice. Addison-Wesley.

Baker, C., Lund, P., Nyathi, R., \& Taylor, J. (2010). The myths surrounding people with albinism in South Africa and Zimbabwe. Journal of African Cultural Studies, 22(2), 169-181.

Basil, M. D. (1996). Identification as a mediator of celebrity effects. Journal of Broadcasting \& Electronic media, 40(4), 478-495.

Braathen, S. H., \& Ingstad, B. (2006). Albinism in Malawi: knowledge and beliefs from an African setting. Disability \& Society, 21(6), 599-611.

Bradbury-Jones, C., Ogik, P., Betts, J., Taylor, J., \& Lund, P. (2018). Beliefs about people with albinism in Uganda: A qualitative study using the Common-Sense Model. PLoS ONE, 13, e0205774. 
Brocco, G. (2015). Labeling albinism: language and discourse surrounding people with albinism in Tanzania. Disability \& Society, 30(1), 1143-1157.

Brocco, G. (2016). Albinism stigma, subjectivity and global-local discourses in Tanzania. Anthropology \& Medicine, 23(3), 229-243. https://doi.org/10.1080/13648470.2016.1184009

Brown, L., Macintyre, K., \& Trujillo, L. (2003). Interventions to reduce HIV/AIDS stigma: What have we learned? AIDS Education and Prevention, 15(1), 49-69.

Brown, S. A., Evans, Y., Espenschade, K., \& O’Connor, M. (2010). An examination of two brief stigma reduction strategies: Filmed personal contact and hallucination simulations. Community Mental Health, 46(5), 494-499.

Bryceson, D. F., Jønsson, J. B., \& Sherrington, R. (2010). Miners' magic: artisanal mining, the albino fetish and murder in Tanzania. The Journal of Modern African Studies, 48(3), 353-382.

Cook, J. E., Purdie-Vaughns, V., Meyer, I. H., \& Busch, J. T. (2013). Intervening within and across levels: A multilevel approach to stigma and public health. Social Science \& Medicine, 103, 101-109.

Corrigan, P. W., Larson, J., Sells, M., Niessen, N., \& Watson, A. C. (2007). Will filmed presentations of education and contact diminish mental illness stigma? Community Mental Health Journal, 43(2), $171-181$.

Corrigan, P. W., Morris, S. B., Michaels, P. J., Rafacz, J. D., \& Rüsch, N. (2012). Challenging the public stigma of mental illness: A meta-analysis of outcome studies. Psychiatric Services, 63(10), 963-973.

Corrigan, P. W., \& O'Shaughnessy, J. R. (2007). Changing mental illness stigma as it exists in the real world. Australian Psychologist, 42(2), 90-97.

Corrigan, P. W., \& Penn, D. L. (1999). Lessons from social psychology on discrediting psychiatric stigma. American Psychologist, 54(9), 765-776.

Corrigan, P. W., River, L. P., Lundin, R. K., Penn, D. L., Uphoff-Wasowski, K., Campion, J., \& Kubiak, M. A. (2001). Three strategies for changing attributions about severe mental illness. Schizophrenia Bulletin, 27(2), 187-195.

Corrigan, P. W., Rowan, D., Green, A., Lundin, R., River, P., \& Uphoff-Wasowski, K. (2002). Challenging two mental illness stigmas: Personal responsibility and dangerousness. Schizophrenia Bulletin, 28(2), 293-309.

Cruz-Inigo, A. E. (2011). Albinism in Africa; Stigma, slaughter and awareness campaigns. Dermatologic Clinics, 29(1), 79-87.

de Groot, T., Peters, R., van Brakel, W., Meurs, P., \& Jacquet, W. (2020). The cultural validation of two scales assessing albinism-related social stigma among high school students in Tanzania. Disability, CBR and Inclusive Development, 30(4), 11-38.

Heijnders, M., \& van der Meij, S. (2006). The fight against stigma: an overview of stigma-reduction strategies and interventions. Psychology, Health \& Medicine, 11(3), 353-363.

Herek, G. M., Capitanio, J. P., \& Widaman, K. F. (2002). HIV-related stigma and knowledge in the United States: Prevalence and trends, 1991-1999. American Journal of Public Health, 92(3), 371-377.

Hong, E. S., Zeeb, H., \& Repacholi, M. H. (2006). Albinism in Africa as a public health issue. BMC Public Health, 6(2), 212.

Imafidon, E. (2017). Dealing with the other between the ethical and the moral: Albinism on the African continent. Theoretical Medicine and Bioethics, 38(2), 163-177.

Koller, M., \& Stuart, H. (2016). Reducing stigma in high school youth. Acta Psychiatrica Scandinavica, 134(S446), 63-70.

Kromberg, J. (2018a). Chapter 2: Clinical features, types of albinism, and natural history. In J. Kromberg \& P. Manga (Eds.), Albinism in Africa (pp. 27-55). Academic Press.

Kromberg, J. G. (2018b). Chapter 9: Psychosocial and cultural aspects of albinism. In J. Kromberg \& P. Manga (Eds.), Albinism in Africa (pp. 171-201). Academic Press.

Kuhlmann, A. K., Kraft, J. M., Galavotti, C., Creek, T. L., Mooki, M., \& Ntumy, R. (2008). Radio role models for the prevention of mother-to-child transmission of HIV and HIV testing among pregnant women in Botswana. Health Promotion International, 23(3), 260-268.

Lookingbill, D. P., Lookingbill, G. L., \& Leppard, B. (1995). Actinic damage and skin cancer in albinos in northern Tanzania: Findings in 164 patients enrolled in an outreach skin care program. Journal of the American Academy of Dermatology, 32(4), 653-658.

Masanja, M. M., Mvena, Z. S., \& Kayunza, K. A. (2014). Albinism: Awareness, attitudes and level of albinos' predicament in Sukumaland, Tanzania. Asian Journal of Applied Science and Engineering, 3(9), 14-27.

Mostert, M. (2016). Stigma as a barrier to the implementation of the Convention of the Rights of Persons with Disabilities in Africa. In C. Ngwena, African Disability Rights Yearbook (pp. 3-24). Pretoria: Pretoria University Law Press. 
Murphy, S. T., Frank, L. B., Moran, M. B., \& Patnoe-Woodley, P. (2011). Involved, transported, or emotional? Exploring the determinants of change in knowledge, attitudes, and behavior in entertainment-eduction. Journal of Communication, 61(3), 407-431.

Penn, D. L., Chamberlin, C., \& Mueser, K. T. (2003). The effects of a documentary film about schizophrenia on psychiatric stigma. Schizophrenia Bulletin, 29(2), 383-391.

Peters, R. M., Zweekhorst, M. B., Bunders, J. F., \& Van Brakel, W. H. (2015). A cluster-randomized controlled intervention study to assess the effect of a contact intervention in reducing leprosy-related stigma in Indonesia. PLoS Neglected Tropical Diseases. https://doi.org/10.1371/journal.pntd.0004003

Pettigrew, T. F. (1998). Intergroup contact theory. Annual Review Psychology, 1, 65-85.

Pettigrew, T. F., \& Tropp, L. R. (2006). A meta-analytic test of intergroup contact theory. Journal of Personality and Social Psychology, 90(5), 751-783.

Reimer-Kirkham, S., Astle, B., Ero, I., Panchuk, K., \& Dixon, D. (2019). Albinism, spiritual and cultural practices, and implications for health, healthcare, and human rights: A scoping review. Disability \& Society, 34, 747-774.

Reinke, R. R., Corrigan, P. W., Leonhard, C., Lundin, R. K., \& Kubiak, M. A. (2004). Examining two aspects of contact on the stigma of mental illness. Journal of Social and Clinical Psychology, 23(3), 377-389.

Ritterfeld, U., \& Jin, S.-A. (2006). Addressing media stigma for people experiencing mental illness using an entertainment-education strategy. Journal of Health Psychology, 11(2), 247-267.

Ritterfeld, U., Klimmt, C., Vorderer, P., \& Steinhilper, L. K. (2005). The effects of a narrative audiotape on preschoolers'entertainment experience and attention. Media Psychology, 7(1), 47-72.

Ritterfeld, U., \& Weber, R. (2006). Video games for entertainment and education. In P. Vorderer \& J. Bryant (Eds.), Playing video game; Motives, responses, and consequences (pp. 399-413). Lawrence Erlbaum Associates Publishers.

Singhal, A., \& Rogers, E. M. (1999). Entertainment-education: A communication strategy for social change. Lawrence Erlbaum.

Slater, M. D., \& Rouner, D. (2002). Entertainment-Education and elaboration likelihood: Understanding the processing of narrative persuasion. Communication Theory, 12(2), 173-191.

Stangl, A. L., Lloyd, J. K., Brady, L. M., Holland, C. E., \& Baral, S. (2012). A systematic review of interventions to reduce HIV-related stigma and discrimination form 2002 to 2013: How far have we come? Journal of the International AIDS Society. https://doi.org/10.7448/IAS.16.3.18734

Tanaka, G., Ogawa, T., Inadomi, H., Kikuchi, Y., \& Ohta, Y. (2003). Effects of an educational program on public attitudes towards mental illness. Psychiatry and Clinical Neuroscience, 57(6), 595-602.

Terwee, C. B., Bot, S. D., de Boer, M. R., van der Windt, D. A., Knol, D. L., Dekker, J., \& de Vet, H. C. (2007). Quality criteria were proposed for measurement properties of health status queestionnaires. Journal of Clinical Epideiology, 60(1), 34-42.

Thornicroft, G., Brohan, E., Kassam, A., \& Lewis-Holmes, E. (2008). Reducing stigma and discrimination: Candidate interventions. International Journal of Mental Health Systems, 2(3), 1-7.

Uromi, S. (2014). Violence against persons with albinism and older women: Tackling witchcraft accusations in Tanzania. International Journal of Education and Research, 2(6), 323-338.

Vorderer, P., Klimmt, C., \& Ritterfeld, U. (2006). Enjoyment: At the heart of media entertainment. Communication Theory, 14(4), 388-408.

Williams, S. E. (2018). Albinism and the eye. In J. Kromberg \& P. Manga (Eds.), Albinism in Africa (pp. 135-148). Academic Press.

Yamaguchi, S., Wu, S., Biswas, M., Madinah, Y., Yuta, A., Barley, E., \& Thornicroft, G. (2013). Effects of short-term interventions to reduce mental health-related stigma in university or college students: a systematic review. The Jounal of Nervous and Mental Disease, 201(6), 490-503.

T. M. M. De Groot her PhD research focused on development and assessment of stigma reduction interventions related to albinism in Tanzania. She completed her $\mathrm{PhD}$ research in Educational Sciences at the Vrije Universiteit Brussels in 2020. Her research interests are social inclusion, healthrelated stigma, stigma reduction intervention, disability, diversity and education. She is currently affiliated with the department of Development \& Education of Youth in Diverse Societies at Utrecht University.

P. Meurs Pieter Meurs holds a masters in Adult Educational Sciences and in Philosopy, and a PhD in Philosophy and Moral Sciences. Currently his research focusses on the political and educational meaning of critical citizenship. He has published on the philosophy of education, phenomenology and globalisation studies in national and international journals. Meurs is affiliated with the department of Educational Sciences at the Vrije Universiteit Brussel and with the department of Social Work at the Erasmushogeschool Brussel. 
Prof Dr. W. Jacquet is an applied mathematician - bio-statistician at the Vrije Universiteit Brussel (VUB), Faculty Medicine \& Pharmacy. He is bio-statistics area coordinator for the Belgian Federal Agency for Medicines and Health Products (FAMHP), observer member of the Bio-statistical Working Party of the European Medicine Agency (EMA). He contributes to the evaluation of marketing applications and scientific advices at national and EMA level. He is co-founder of the research unit Localities Ontologies Commons Integrated (LOCI) of the Faculty of Psychology and Educational Sciences (VUB). His major scientific interest is the application of statistics and the development of measurements systems both from a practical and a theoretical point of view.

Dr. R. M. H. Peters is an Assistant Professor at Vrije Universiteit Amsterdam. She defended her PhD thesis on stigma reduction in leprosy in 2015. Her research interests are health-related stigma, disability and inclusion. 